\title{
Uncaria rhynchophylla Induces Angiogenesis in Vitro and in Vivo
}

\author{
Do-Young Chor,${ }^{a}$ Jeong-Eun Huh,${ }^{b}$ Jae-Dong Lee, ${ }^{a}$ Eun-Mi Cho, ${ }^{b}$ Yong-Hyeon BAeK, ${ }^{a}$ \\ Ha-Ru YANG, ${ }^{b}$ Yoon-Je ChO, ${ }^{c}$ Kang-Il KIM, ${ }^{c}$ Deog-Yoon KIM, ${ }^{d}$ and Dong-Suk PARK ${ }^{*, a}$ \\ ${ }^{a}$ Department of Acupuncture \& Moxibustion, College of Oriental Medicine; ${ }^{b}$ Oriental Medicine Research Center for Bone \\ \& Joint Disease; ${ }^{c}$ Department of Orthopedic Surgery, College of Medicine; and ${ }^{d}$ Department of Nuclear Medicine, \\ College of Medicine, Kyung Hee University; 1 Hoegidong, Dongdaemungu, Seoul 130-701, Korea. \\ Received June 13, 2005; accepted September 6, 2005
}

\begin{abstract}
Angiogenesis consists of the proliferation, migration, and differentiation of endothelial cells, and angiogenic factors and matrix protein interactions modulate this process. The aim of this study was to determine the angiogenic properties of Uncaria rhynchophylla. Uncaria rhynchophylla significantly enhanced human umbilical vein endothelial cells (HUVECs) proliferation in a dose-dependent manner. Neutralization of vascular endothelial growth factor (VEGF) or basic fibroblast growth factor (bFGF) by monoclonal antibody suppressed the Uncaria rhynchophylla stimulatory effect on proliferation. In addition, Uncaria rhynchophylla significantly increased chemotactic-migration on gelatin and tubular structures on Matrigel of HUVECs in a dose-dependent manner. Interestingly, Uncaria rhynchophylla dose-dependently increased VEGF, and bFGF gene expression and protein secretion of HUVEC. The angiogenic activity of Uncaria rhynchophylla was confirmed using an in vivo Matrigel angiogenesis model, showing promotion of blood vessel formation. These results suggest that Uncaria rhynchophylla could potentially used to accelerate vascular wound healing or to promote the growth of collateral blood vessel in ischemic tissues.
\end{abstract}

Key words Uncaria rhynchophylla; angiogenesis; Matrigel plug assay; proliferation; migration; tube formation; basic fibroblast growth factor (bFGF); vascular endothelial growth factor (VEGF)

Angiogenesis is the process of forming new capillary blood vessels from preexisting vasculature, leading to neovascularization, and is a tightly controlled process. ${ }^{1,2}$ Abnormal angiogenesis participates in tumor development and angioproliferative diseases. ${ }^{3)}$ However, pharmacological stimulation of angiogenesis could be used to accelerate vascular wound healing and promote the growth of collateral blood vessels in ischemic tissues. ${ }^{4,5)}$ Angiogenesis is stimulated by a large number of growth factors, notably including vascular endothelial growth factor (VEGF), basic fibroblast growth factor (bFGF, FGF-2), which promotes several aspects of the angiogenic process and in a variety of developmental process. $^{6-8)}$ FGF-2 is mainly released by damaged cells at wound edges. ${ }^{9)}$ VEGF production is upregulated in hypoxic conditions such as those found in ischemic tissues. ${ }^{10)}$ In response to angiogenic growth factors, endothelial cells degrade the basement membrane of the parent vessel, migrate into the surrounding intercellular matrix towards angiogenic stimulus, proliferate to prolong new blood vessels, and differentiate into contiguous tubular sprouts which subsequently anastomose to form functional capillary loops. ${ }^{2,11)}$ Recent studies have shown that the use of bFGF, and VEGF as a therapeutic agent for the treatment of wound healing, ${ }^{12)}$ ischemic cardiovascular disease ${ }^{13,14)}$ and bone fracture healing $^{15)}$ in vivo model. In addition, a potential alternative strategy may be to use drugs with angiogenic activity that are available in oral formulations and that are currently administered to patients for treatment of different pathologies. ${ }^{16)}$

Uncaria rhynchophylla has been used for suppression of liver hyperfunction, relief of dizziness, treatment of tremors and convulsions, general health, and ischemic heart disease in Oriental medicine. However, these functions have not been scientifically tested and their mechanisms are not known. It is known to have sedative and anticonvulsive effects and has thus been applied in the treatment of epilepsy. ${ }^{17)}$ Recently, it was reported that the alkaloid fraction of Uncaria rhynchophylla protects $N$-methyl-D-aspartate (NMDA)-induced neuronal cell death by suppressing apoptosis-related genes. ${ }^{18)}$ However, much more insight into the pharmacological functions and mechanisms of Uncaria rhynchophylla are needed, especially as there is no clear experimental evidence supporting its use in the treatment of wound healing and cardiovascular diseases.

In this study, we attempted to identify and characterize whether Uncaria rhynchophylla could induces angiogenesis in vitro and in vivo.

\section{MATERIALS AND METHODS}

Preparation of Uncaria rhynchophylla Extract The root of Uncaria rhynchophylla was extracted at room temperature in $70 \%(\mathrm{v} / \mathrm{v})$ ethanol in water for $12 \mathrm{~h}$. The extract was then filtered and concentrated under low pressure using a rotary vacuum evaporator (Eyela, Japan). The residue was lyophilized in a freeze dryer, and stored at $-20^{\circ} \mathrm{C}$. This powder, dissolved in dimethylsulfoxide (DMSO), was used for experiments with the final concentration of DMSO in the culture medium adjusted to below $0.5 \%$.

Isolation and Culture of Human Umbilical Vein Endothelial Cells (HUVECs) HUVECs were obtained by an established method from freshly delivered umbilical cords. In brief, human umbilical cord veins were cannulated and flushed with cold phosphate buffered saline (PBS) containing $0.2 \%$ glucose to remove blood and then filtered with $0.2 \%$ type II collagenase (Sigma-Aldrich Co., MO, U.S.A.) in PBS for $10 \mathrm{~min}$ at $37^{\circ} \mathrm{C}$. After pelleting and resuspending the cells, they were plated in a $75 \mathrm{~cm}^{2}$ tissue culture flask coated with $0.1 \%$ gelatin, cultured with $\mathrm{EGM}^{\mathrm{TM}}-2$ complete medium (Cambrex, MD, U.S.A.), and incubated at $37^{\circ} \mathrm{C}$ in $5 \% \mathrm{CO}_{2}$. Once confluent, the cells were detached using a 
trypsin-EDTA solution and used in experiments from the third to sixth passages.

Cell Proliferation Assay HUVECs were plated at a density of $5 \times 10^{3}$ cells/well in $\mathrm{EGM}^{\mathrm{TM}}-2$ medium in 96-well plates. After $24 \mathrm{~h}$, the medium was removed and replaced with EBM (Cambrex Inc., MD, U.S.A.) plus $2 \%$ FBS, and 3 units/ml of heparin (control medium). For Uncaria rhynchophylla proliferation study, cells were treated with 0.01 , $0.1,1,10,100 \mu \mathrm{g} / \mathrm{ml}$ of Uncaria rhynchophylla, $25 \mathrm{ng} / \mathrm{ml}$ VEGF (R\&D systems Inc., MN, U.S.A.), or $5 \mathrm{ng} / \mathrm{ml}$ of bFGF (R\&D Systems Inc., MN, U.S.A.). For neutralization study of HUVEC proliferation by Uncaria rhynchophylla, cells were pre-treated with $50 \mathrm{ng} / \mathrm{ml}$ of goat anti-VEGF IgG (Santa Cruz Biotechnology, Inc., CA, U.S.A.), or $20 \mathrm{ng} / \mathrm{ml}$ of goat anti-bFGF IgG (Santa Cruz Biotechnology, Inc., CA, U.S.A.) for $1 \mathrm{~h}$, and then add $100 \mu \mathrm{g} / \mathrm{ml}$ of Uncaria rhynchophylla. After $72 \mathrm{~h}$ incubation, $10 \mu \mathrm{l}$ of BrdU were added to each well, and the plates were incubated for a further $6 \mathrm{~h}$ at $37^{\circ} \mathrm{C}$. Cells were fixed, and anti-BrdU-POD was then added and detected by the TMB substrate reaction. This reaction was quantified using an ELISA reader at $450 \mathrm{~nm}$ and $690 \mathrm{~nm}$. Results were calculated as a percentage of viable cells in the Uncaria rhynchophylla-treated groups relative to the $0.5 \%$ DMSO-treated control.

Chemotaxis Migration Assay Polyvinylpyrrolidonefree polycarbonate filters, pore size $12 \mu \mathrm{m}$ (Neuro Probe Inc., MD, U.S.A.), were coated with $0.1 \%$ gelatin and allowed to air dry. The lower compartments of Boyden chambers were filled with $1 \times 10^{6}$ cells in EBM plus 3 units $/ \mathrm{ml}$ of heparin. The chambers were incubated at $37^{\circ} \mathrm{C}$ for $2 \mathrm{~h}$, and then different concentration of Uncaria rhynchophylla, $25 \mathrm{ng} / \mathrm{ml}$ VEGF, or $5 \mathrm{ng} / \mathrm{ml} \mathrm{bFGF}$ were loaded into the upper compartments of the chambers being tested. The Boyden chambers were re-incubated at $37^{\circ} \mathrm{C}$ for $2 \mathrm{~h}$, and then the filters were removed, fixed, and stained with Diff-Quik (Sysmex Co., Kobe, Japan). Cells on the lower surface of the filter were wiped off with a swab and the cells on the upper surface, which had migrated across the filter, were counted. Stained filters were photographed under a microscope $(200 \times, \mathrm{Ax}-$ iovert 200, ZEISS, Germany), and the cells were quantified by counting the number of cells per field. Each assay was conducted in triplicate and experiments were repeated at least 3 times.

Tube Formation Assay on Matrigel Unpolymerized Matrigel (Collaborative Biomedical Products, MA, U.S.A.) was added to 24 -well plates, with a total volume of $300 \mu \mathrm{l}$ in each well, and allowed to polymerize for $30 \mathrm{~min}$ at $37^{\circ} \mathrm{C}$. Various concentrations of Uncaria rhynchophylla, $25 \mathrm{ng} / \mathrm{ml}$ VEGF, or $5 \mathrm{ng} / \mathrm{ml} \mathrm{bFGF} \mathrm{were} \mathrm{plated} \mathrm{onto} \mathrm{the} \mathrm{layer} \mathrm{of} \mathrm{Ma-}$ trigel at a density of $1 \times 10^{5}$ cells/well in control medium. After $8 \mathrm{~h}$, cells were photographed, and the extent of tube formation was analyzed using the Scion image program.

Gene Expression of RT-PCR RNA was prepared with Trizol $^{\circledR}$ reagent (Invitrogen Corporation, CA, U.S.A.). Reverse transcription of $1 \mu \mathrm{g}$ of total RNA was carried out for $60 \mathrm{~min}$ at $42^{\circ} \mathrm{C}$ and then $15 \mathrm{~min}$ at $72^{\circ} \mathrm{C}$, using the system for RT-PCR (TaKaRa Biotechnology, Seoul, Korea), PCR using specific primers for each cDNA was carried out in a PCR reaction volume of $10 \mu \mathrm{l}$ (as supplied by TaKaRa, Korea). Amplification reactions were performed using VEGF (R\&D Systems Inc., MN, U.S.A.), bFGF primer (R\&D Sys- tems Inc., MN, U.S.A.), following protocol. An equal volume from each PCR was analyzed by $1.5 \%$ agarose gel electrophoresis, and ethidium bromide-stained PCR products were evaluated. Marker gene expression was normalized to $\beta$-actin expression in each sample. Signal intensity was quantified with the Gel Doc EQ (BIO-RAD Laboratories, Milan, Italy).

Measurement of VEGF and bFGF Culture supernatants were individually collected and frozen at $-70^{\circ} \mathrm{C}$ before immunoassay of VEGF and bFGF with a commercially available enzyme-linked immunosorbent assay (ELISA) kit (R\&D Systems Inc., MN, U.S.A.). Samples were assayed in triplicate and calibrated against VEGF and bFGF standards.

In Vivo Mouse Matrigel Plug Assay Six-week-old male C57BL/6 mice were injected subcutaneously with $0.5 \mathrm{ml}$ of Matrigel alone, Matrigel plus $50 \mu \mathrm{g} / \mathrm{ml}$ of Uncaria rhynchophylla or $100 \mathrm{ng}$ of bFGF per mouse, along with $10 \mathrm{units} / \mathrm{ml}$ of heparin. After $7 \mathrm{~d}$, the mice were sacrificed, and the Matrigel plug was removed, fixed with $10 \%$ formalin and embedded in paraffin. Sections from the plugs were stained with hematoxylin and eosin for microscopic observation. Pathologists with no prior knowledge of the test agents examined the stained sections. To quantify the formation of new blood vessels, the amount of hemoglobin $(\mathrm{Hb})$ present was measured using a hemoglobin reagent kit (Youngdong Diagnotics, Youngin, Korea) according to the supplier's protocol. The concentration of $\mathrm{Hb}$ was calculated by reference to a known amount of $\mathrm{Hb}$ provided in the kit.

Statistical Analysis The results are expressed as means \pm S.D., as calculated from the specified number of determinations. Data comparisons were performed using Student's $t$-test. Significance was defined as a $p$ value of $<0.05$.

\section{RESULTS}

Effect of Uncaria rhynchophylla on Proliferation To investigate the angiogenic activity of Uncaria rhynchophylla in detail, the dose of Uncaria rhynchophylla with the optimum effect on endothelial cell growth was first determined. A range of $0-100 \mu \mathrm{g} / \mathrm{ml}$ Uncaria rhynchophylla was applied to the HUVECs. Uncaria rhynchophylla induced the growth of HUVECs in a dose-dependent manner, and endothelial cell proliferation was seen even at relatively low doses (Fig. 1A). Uncaria rhynchophylla at $0.1 \mu \mathrm{g} / \mathrm{ml}$ significantly increased cell proliferation by $21.2 \%$, and at $10 \mu \mathrm{g} / \mathrm{ml}$ the proliferative effect was further increased to $44.5 \%$ (Fig. 1A). To test whether Uncaria rhynchophylla HUVEC proliferation could be due to possible traces of growth factors, we next examined the effect of on proliferation in the presence or absence of antibodies against VEGF and bFGF. Addition of these antibodies against VEGF and bFGF inhibited proliferation induced Uncaria rhynchophylla (Fig. 1B).

Effect of Uncaria rhynchophylla on Migration The effect of Uncaria rhynchophylla on endothelial cell migration were examined. Under Uncaria rhynchophylla-free conditions, the number of migrating cells was $9.8 \pm 2.3$ cells/field. Uncaria rhynchophylla induced the migration cell of HUVECs in a dose-dependent manner (Fig. 2). Especially, Uncaria rhynchophylla at $25 \mu \mathrm{g} / \mathrm{ml}$ markedly enhanced cell migration, the number of migrating cells was $94.8 \pm 3.1$ cells/field, a significant 9.7-fold induction compared with 
(A)

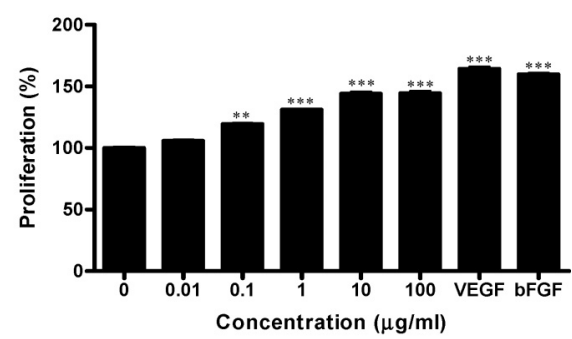

(B)

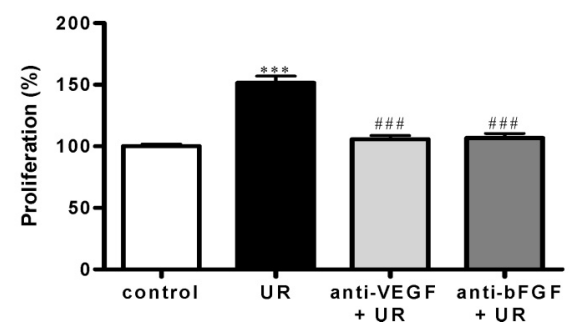

Fig. 1. Effects of Uncaria rhynchophylla on Proliferation of HUVECs

(A) HUVECs were plated in 96-well plates, allowed to attach for $24 \mathrm{~h}$, and then treated with indicated concentrations of Uncaria rhynchophylla, $25 \mathrm{ng} / \mathrm{ml}$ VEGF, or $5 \mathrm{ng} / \mathrm{ml} \mathrm{bFGF}$ for $72 \mathrm{~h}$. (B) HUVECs pretreated with $50 \mathrm{ng} / \mathrm{ml}$ goat anti-VEGF IgG, or $20 \mathrm{ng} / \mathrm{ml}$ anti-bFGF IgG for $1 \mathrm{~h}$ before added $100 \mu \mathrm{g} / \mathrm{ml}$ Uncaria rhynchophylla. Cells were further incubated and proliferation as determined by a colorimetric BrdU assay. Data are expressed as percentage change of raw data. Results are shown as the mean \pm S.D. of three experiments. $* * p<0.01, * * * p<0.001$ compared with control, and \#\# $p<0.001$ compared with Uncaria rhynchophylla.

control (Fig. 2). In the positive control, VEGF at $25 \mathrm{ng} / \mathrm{ml}$, and $\mathrm{bFGF}$ at $10 \mathrm{ng} / \mathrm{ml}$, the number of migrating cells 103.5 \pm 5.6 , and 105.3 \pm 6.3 cells/field, showing each of 10.6, and 10.7-fold induction compared with control (Fig. 2).

Effect of Uncaria rhynchophylla on Tube-Like Formation The stimulatory potency of Uncaria rhynchophylla on the differentiation of endothelial cells into tube-like structures was tested. Under Uncaria rhynchophylla-free condition, the mean intensity of HUVEC tube-like structures formed was $396877 \pm 43.5$; whereas in the presence of $U n$ caria rhynchophylla significantly increased tube-like structures formation in a dose dependent manner. Uncaria rhynchophylla at $10 \mu \mathrm{g} / \mathrm{ml}$, the mean intensity of tube-like structures formed was $1636000 \pm 334.3$ tubes/field, a 4.1 -fold stimulation compared with control (Fig. 3).

Effect of Uncaria rhynchophylla on VEGF and bFGF Expression To analyze further the effect of Uncaria rhynchophylla on HUVEC proliferation, we tested the ability of Uncaria rhynchophylla to modulate the expression of VEGF and bFGF message and protein of HUVEC (Fig. 4). Uncaria rhynchophylla increased VEGF $\left(\mathrm{VEGF}_{164}\right.$, and $\left.\mathrm{VEGF}_{120}\right)$, and bFGF gene expression in a dose-dependent manner. In contrast, the level of $\beta$-actin was not changed by incubation with various concentrations of Uncaria rhynchophylla (Fig. 4A). Also, Uncaria rhynchophylla significantly increased VEGF and bFGF secretion of HUVEC in a dose-dependent manner (Fig. 4B).

Effect of Uncaria rhynchophylla on in Vivo Angiogenic Activity The angiogenic activity of Uncaria rhynchophylla was investigated in an established in vivo angiogenesis model, the Matrigel plug assay. Matrigel plugs were evaluated for vessel/network formation and hemoglobin $(\mathrm{Hb})$ con-
(A)

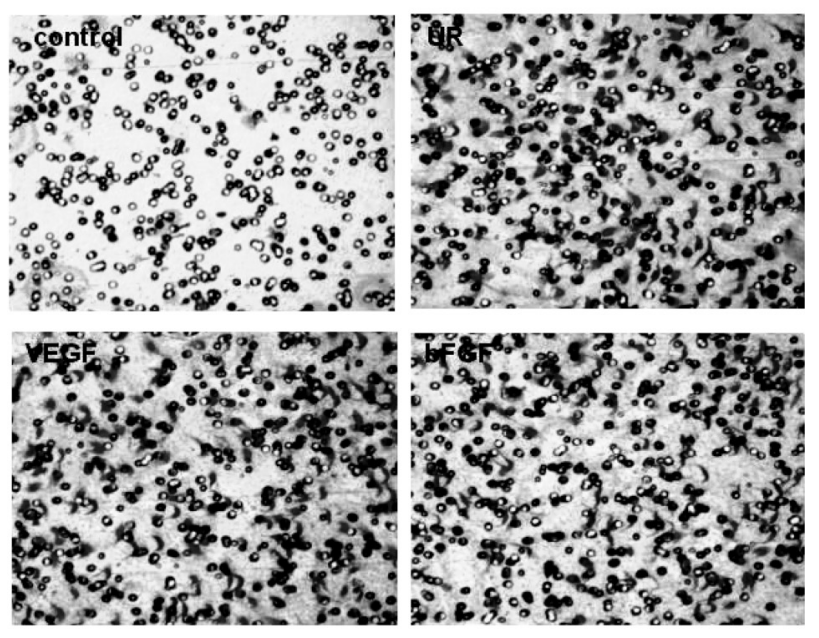

(B)

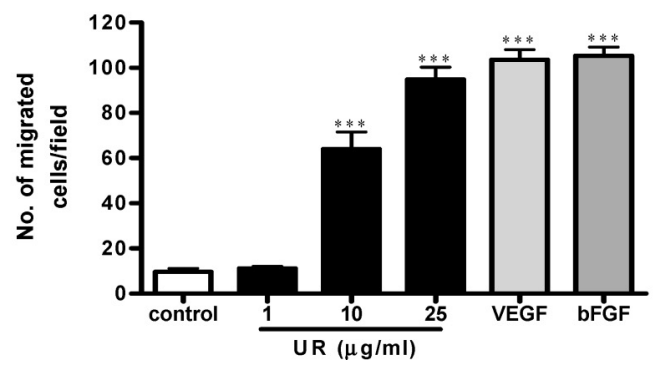

Fig. 2. Effects of Uncaria rhynchophylla on Migration of HUVECs

(A) HUVECs were treated with different concentration of Uncaria rhynchophylla, $25 \mathrm{ng} / \mathrm{ml}$ VEGF, or $10 \mathrm{ng} / \mathrm{ml}$ bFGF. A modified Boyden chamber was used to assess migratory activity of photomicrographs (magnification, $200 \times$ ) of a representative experimental result was shown. Untreated HUVECs (control), $25 \mu \mathrm{g} / \mathrm{ml}$ Uncaria rhynchophylla (UR), $25 \mathrm{ng} / \mathrm{ml}$ VEGF, or $10 \mathrm{ng} / \mathrm{ml}$ bFGF. (B) Migrated cells were counted in at least four fields after each assay, and data are expressed as the number of cells per field. Data are expressed as the mean \pm S.D. of three independent experiments. $* * * p<0.001$ compared with control.

tent. In the histological examination, Matrigel control plugs containing bFGF showed tube/network formation. In addition, Uncaria rhynchophylla strongly induced angiogenesis (Fig. 5A). The $\mathrm{Hb}$ content was $5.7 \pm 0.44 \mathrm{~g} / \mathrm{dl}$ in control plugs and $10.5 \pm 3.4 \mathrm{~g} / \mathrm{dl}$ in bFGF $100 \mathrm{ng}$ plugs. The $\mathrm{Hb}$ level in plugs containing Uncaria rhynchophylla at $50 \mu \mathrm{g} / \mathrm{ml}$ was significantly increased to $10.8 \pm 3.9 \mathrm{~g} / \mathrm{dl}$ (Fig. 5B).

\section{DISCUSSION}

In this study, we have shown the angiogenic properties of Uncaria rhynchophylla. Despite a long history in Oriental medicine of using Uncaria rhynchophylla as a therapeutic agent in wound healing, ischemia, and the experience-based perception that such treatments might be beneficial, there is no clear experimental evidence supporting this speculation. Therefore, we evaluated whether Uncaria rhynchophylla would promote angiogenesis in vitro and in vivo.

Our data showing that Uncaria rhynchophylla moderately enhances HUVEC proliferation, and significantly suppress Uncaria rhynchophylla stimulatory effect by neutralization of goat VEGF or bFGF antibody (Fig. 1). To determine the specific effect of Uncaria rhynchophylla on endothelial cells, we attempted chemotactic migration and capillary tube-like 
(A)
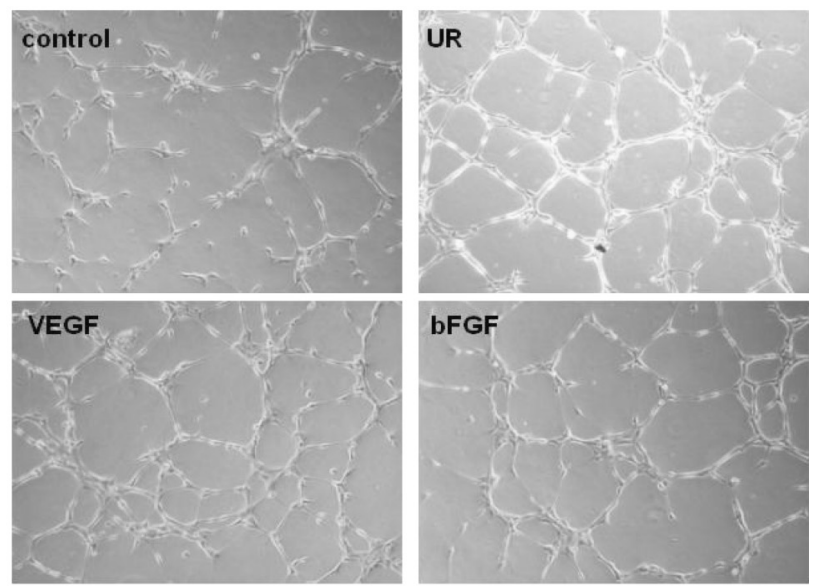

(B)

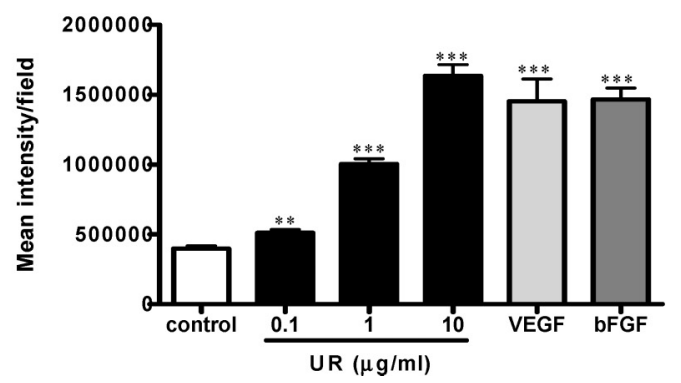

Fig. 3. Effects of Uncaria rhynchophylla on Tube-Like Formation in HUVECs

(A) HUVECs were treated with different concentration of Uncaria rhynchophylla, $25 \mathrm{ng} / \mathrm{ml} \mathrm{VEGF}$, or $10 \mathrm{ng} / \mathrm{ml} \mathrm{bFGF}$ on Matrigel. After incubation for $8 \mathrm{~h}$ and fixation, cells were observed under the microscope (magnification, 100×) and photographed. Digital image of untreated HUVECs (control), $10 \mu \mathrm{g} / \mathrm{ml}$ Uncaria rhynchophylla (UR), $25 \mathrm{ng} / \mathrm{ml}$ VEGF, or $10 \mathrm{ng} / \mathrm{ml} \mathrm{bFGF}$. (B) Tubes were counted per field in at least four fields after each experiment, and results were expressed as the number of tubes formed. Data are expressed as the mean \pm S.D. of three independent experiments. $* * p<0.01$, $* * * p<0.001$ compared with control.

formation assays, and Uncaria rhynchophylla strongly induced endothelial cell migration, and tube-like formation in a dose-dependent manner (Figs. 2, 3). Our data showed that the stimulation of HUVEC growth by Uncaria rhynchophylla occurred at concentrations lower than the concentrations needed to induce cell migration on gelatin and tube formation on Matrigel. This result expected that the induction of angiogenesis by Uncaria rhynchophylla might initially be induced by stimulation of HUVEC proliferation.

To confirm the angiogenic activity of Uncaria rhynchophylla through stimulation of HUVEC proliferation, we measured growth factors such as VEGF and bFGF gene expression and protein secretion of HUVEC. Uncaria rhynchophylla significantly induced bFGF and VEGF expression in a dose-dependent manner by RT-PCR and ELISA analysis (Fig. 4). This result implies that the expression of bFGF and VEGF induced by Uncaria rhynchophylla is closely related to the angiogenic activity of HUVECs. Recently, it has been reported that the angiogenic effect of bFGF and VEGF is related heparin-binding growth factor family, could be used to promotes wound healing. ${ }^{19)}$ Also, endogenous and exogenous FGF-2 accelerates wound healing in a chick embryo chorioallantoic membrane in vivo model. ${ }^{20)}$ In addition, it has
(A)

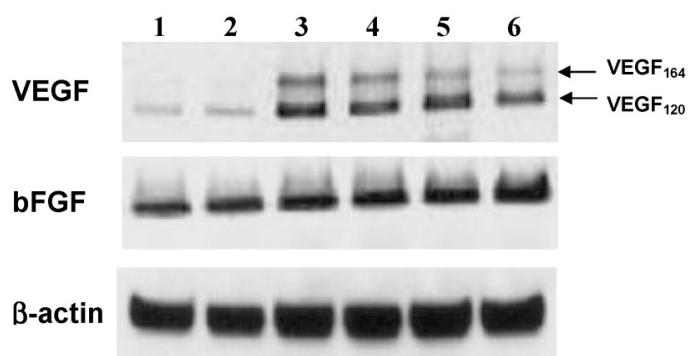

(B)
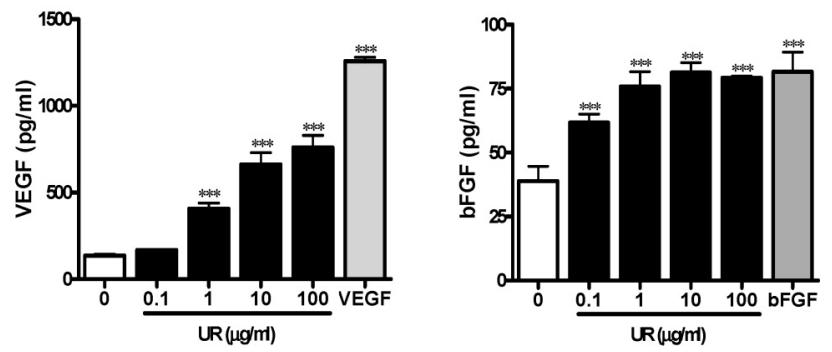

Fig. 4. Effects of Uncaria rhynchophylla on Expression of VEGF and bFGF by HUVECs

(A) HUVECs were treated with Uncaria rhynchophylla at the various concentrations, $25 \mathrm{ng} / \mathrm{ml} \mathrm{VEGF}, 10 \mathrm{ng} / \mathrm{ml} \mathrm{bFGF}$ for $24 \mathrm{~h}$. Expression of VEGF and bFGF RNA message were assayed RT-PCR. Lane 1 ; control, $2 ; 0.1 \mu \mathrm{g} / \mathrm{ml}, 3 ; 1 \mu \mathrm{g} / \mathrm{ml}, 4 ; 10 \mu \mathrm{g} / \mathrm{ml}, 5$; $100 \mu \mathrm{g} / \mathrm{ml}$ Uncaria rhynchophylla, $6 ; 25 \mathrm{ng} / \mathrm{ml}$ VEGF or $10 \mathrm{ng} / \mathrm{ml} \mathrm{bFGF}$. (B) HUVECs were treated for $72 \mathrm{~h}$ with different concentration of Uncaria rhynchophylla, $25 \mathrm{ng} / \mathrm{ml}$ VEGF, or $10 \mathrm{ng} / \mathrm{ml} \mathrm{bFGF}$. Production of VEGF and bFGF in conditioned medium assayed by ELISA. Values were determined in triplicate and calibrated against a VEGF and bFGF standard. Each value represents mean \pm S.D. $* * * p<0.001$ compared with control.
(A)

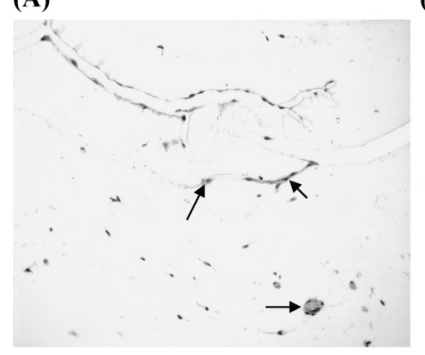

(C)

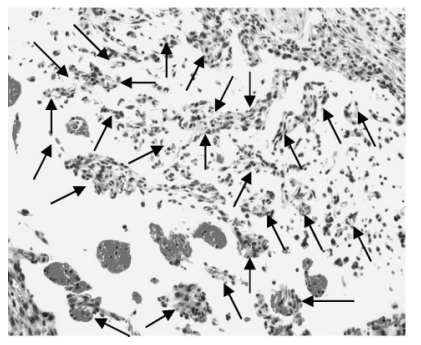

(B)

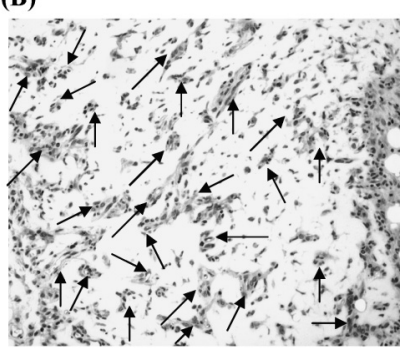

(D)

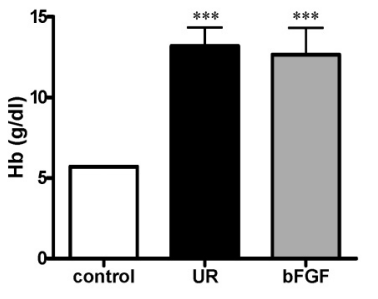

Fig. 5. Effects of Uncaria rhynchophylla on Angiogenesis Matrigel Plug Assay

Uncaria rhynchophylla $50 \mu \mathrm{g} / \mathrm{ml}$ or bFGF $100 \mathrm{ng}$ plus $10 \mathrm{units} / \mathrm{ml}$ of heparin were mixed with Matrigel, and $0.5 \mathrm{ml}$ of the mixture was injected subcutaneously into C57BL/6J mice. After $7 \mathrm{~d}$, mice were sacrificed and the Matrigel plugs were excised. Sectioned Matrigel was stained with hematoxylin and eosin for microscopic observation. (A) Control (only Matrigel), (B) UR, and (C) bFGF. (D) Matrigel plugs were tested for hemoglobin $(\mathrm{Hb})$ content to quantify the formation of functional blood vessels. Values shown are mean \pm S.D. $* * * p<0.01$ compared with control. 
been demonstrated that the healing of excisional skin wounds is delayed in mice lacking FGF-2. ${ }^{21)}$ Research in animal models of ischemia has shown that administration of bFGF and VEGF promotes the development of neovascularization in collateral blood vessels. ${ }^{22,23)}$ Ex vivo gene therapy has enabled researchers to develop therapeutic angiogenesis strategies applied to an animal model of myocardial ischemia associated with capillary neovascularization. ${ }^{24)}$ Futhermore, in vivo models of bone fracture have demonstrated that the addition of exogenous FGF-2 to a fracture site or bone defect during the early healing stage accelerates fracture repair and bone formation. ${ }^{25,26)}$

We observed that Uncaria rhynchophylla promotes in vivo angiogenesis in a model in which Uncaria rhynchophylla-impregnated Matrigel implants led to an greatly increase in tube/network formation and $\mathrm{Hb}$ content compared with bFGF (Fig. 5). This in vivo result Uncaria rhynchophylla is supported by in vitro studies showing that stimulates in vitro HUVEC cell proliferation and migration as well as the formation of capillary-like structures that play an essential role in the angiogenesis process.

These data present the first pharmacological evidence that Uncaria rhynchophylla significantly induces angiogenesis in vitro and in vivo. In addition, it is expected that this study will allow better understanding of the relationship between angiogenesis and wound healing, and ischemia control by Uncaria rhynchophylla in Oriental medicines. In conclusion, these results show that Uncaria rhynchophylla is a potent angiogenic agent and a promising drug for the induction of neovascularization. Therefore, we propose that it is still necessary to isolate an effective compound from Uncaria rhynchophylla in the future research.

Acknowledgements This study was supported by a grant of the Oriental Medicine R\&D Project, Ministry of Health \& Welfare, Republic of Korea (03-PJ9-PG6-SO010002).

\section{REFERENCES}

1) Folkman J., Shing Y., J. Biol. Chem., 267, 10931-10934 (1992).

2) Furcht L.T., Lab. Invest., 55, 505-509 (1986).
3) Folkman J., Nature Med., 1, 27-31 (1995).

4) Detillieux K. A., Sheikh F., Kardami E., Cattini P. A., Cardiovasc. Res., 57, 8-19 (2003).

5) Heilmann C., Beyersdorf F., Lutter G., Cardiovasc. Surg., 10, 570578 (2002).

6) Ferrara N., Houck K., Jakeman L., Leung D. W., Endocr. Rev., 13, 18-32 (1992).

7) Schweigerer L., Neufeld G., Friedman J., Abraham J. A., Fiddes J. C., Gospodarowicz D., Nature (London), 325, 257-259 (1987).

8) Voldavsky I., Folkman J., Sullivan R., Fridman R., Ishai-michaeli R., Sasse J., Klagsbrun M., Proc. Natl. Acad. Sci. U.S.A., 84, 2292-2296 (1987).

9) Me Neil P. L., Muthukrishnan L., Warder E., D’Armore P. A., J. Cell Biol., 109, 811-822 (1989).

10) Heba G., Krzeminski T., Pore M., Grzyb J., Ratajska A., DembinskaKiec A., J. Vasc. Res., 38, 288-300 (2001).

11) Marti H. H., Risau W., Thromb. Haemost., 82 (Suppl. 1), 44-52 (1999).

12) Tsuboi R., Rifkin D. B., J. Exp. Med., 172, 245-251 (1990).

13) Murayama T., Tepper O. M., Silver M., Ma H., Losordo D. W., Isner J. M., Asahara T., Kalka C., Exp. Hemat., 30, 967-972 (2002).

14) Horvath K. A., Doukas J., Lu C. Y., Belkind N., Greene R., Pierce G. F., Fullerton D. A., Ann. Thorac. Surg., 74, 481-486 (2002).

15) Nakamura K., Kawaguchi H., Aoyama I., Hanada K., Hiyama Y., Awa T., Tamura M., Kurokawa T., J. Ortho. Res., 15, 307-313 (1997).

16) Silvestre J. S., Levy B. I., Bull. Acad. Nat. Med., 188, 649-659 (2004).

17) Hsieh C. L., Chen M. F., Li T. C., Li S. C., Tang N. Y., Hsieh C. T., Pon C. Z., Lin J. G., Am. J. Chin. Med., 27, 257-264 (1999).

18) Lee J., Son D., Lee P., Kim S. T., Kim H., Kim C. J., Lim E., Neurosci. Lett., 348, 51-55 (2003).

19) Matou S., Colliec-Jouault S., Galy-Fauroux I., Ratiskol J., Sinquin C., Guezennec J., Fischer A. M., Helley D., Biochem. Pharmacol., 69, $751-759$ (2005).

20) Ribatti D., Nico B., Vacca A., Roncali L., Presta M., Angiogenesis, 3, 89-95 (1999).

21) Ortega S., Ittmann M., Tsang S. H., Ehrlich M., Basilico C., Proc. Natl. Acad. Sci. U.S.A., 95, 5672-5677 (1998).

22) Laham R. J., Garcia L., Baim D. S., Post M., Simons M., Curr. Inter. Cardio. Rep., 1, 228-233 (1999).

23) Marui A., Kanematsu A., Yamahara K., Doi K., Kushibiki T., Yamamoto M., Itoh H., Ikeda T., Tabata Y., Komeda M., J. Vasc. Surg., 41, 82-90 (2005).

24) Ninomiya M., Koyama H., Miyata T., Hamada H., Miyatake S., Shigematsu H., Takamoto S., Gene Ther., 10, 1152-1160 (2003).

25) Nakamura T., Hara Y., Tawaga M., Tamura M., Yuge T., Fukuda H., Nigi H., J. Bone Miner. Res., 13, 942-949 (1998).

26) Kawaguchi H., Nakamura K., Tabata Y., Ikada Y., Aoyama I., Anzai J., Nakamura T., Hiyama Y., Tamura M., J. Clin. Endocrinol. Metab., 86, $875-880$ (2001). 